\title{
Traction-assisted hybrid endoscopic submucosal dissection for small rectal neuroendocrine tumors
}

Endoscopic resection is conducted as a first-line treatment for localized small rectal neuroendocrine tumors (NETs) [13]. However, NETs involve the deep mucosa and submucosa; a sufficient tumorfree vertical margin is required for $\mathrm{R} 0$ resection in endoscopic treatment. $\mathrm{Re}$ cently, we developed the traction-assisted hybrid endoscopic submucosal dissection (ESD) procedure for gastrointestinal tumors [4]. Herein, we present a case of a small rectal NET successfully treated by traction-assisted hybrid ESD ( $\vee$ Video 1 ). A subepithelial lesion $10 \mathrm{~mm}$ in size was detected in the rectum. Endoscopic ultrasonography revealed that the tumor was located within the submucosal layer. Therefore, traction-assisted hybrid ESD using a multifunctional snare (SOUTEN; Kaneka Medix, Tokyo, Japan) was performed for this lesion. Marking dots were made by coagulation with the distal tip of the SOUTEN. Hyaluronic acid was injected into the submucosal layer around the lesion using an injection needle. Thereafter, circumferential mucosal incision and trimming of the submucosal layer were performed using the tip of the SOUTEN [5]. Subsequently, a clip-withthread was placed at the anal mucosal flap of the lesion ( $\mathbf{F i g . 1} \mathbf{a}$ ). The thread was passed through a ring of the snare inserted through a biopsy channel ( Fig.1b). After endoscope insertion, the thread was straightened ( $\nabla$ Fig. $1 \mathbf{c}$, d). With the snare open, the thread was pulled until the lesion was adequately elevated to snare the deep submucosal layer (> Fig. 2). The cutting mode was selected for snare resection to avoid hypercoagulation of the submucosa below the tumor cells. En bloc resection of the lesion was achieved without complications. Histological assessment showed a differentiated NET with tumor-free lateral and vertical margins. There remained an $800-\mu \mathrm{m}$ distance from the lesion edge to the vertical resection margin.

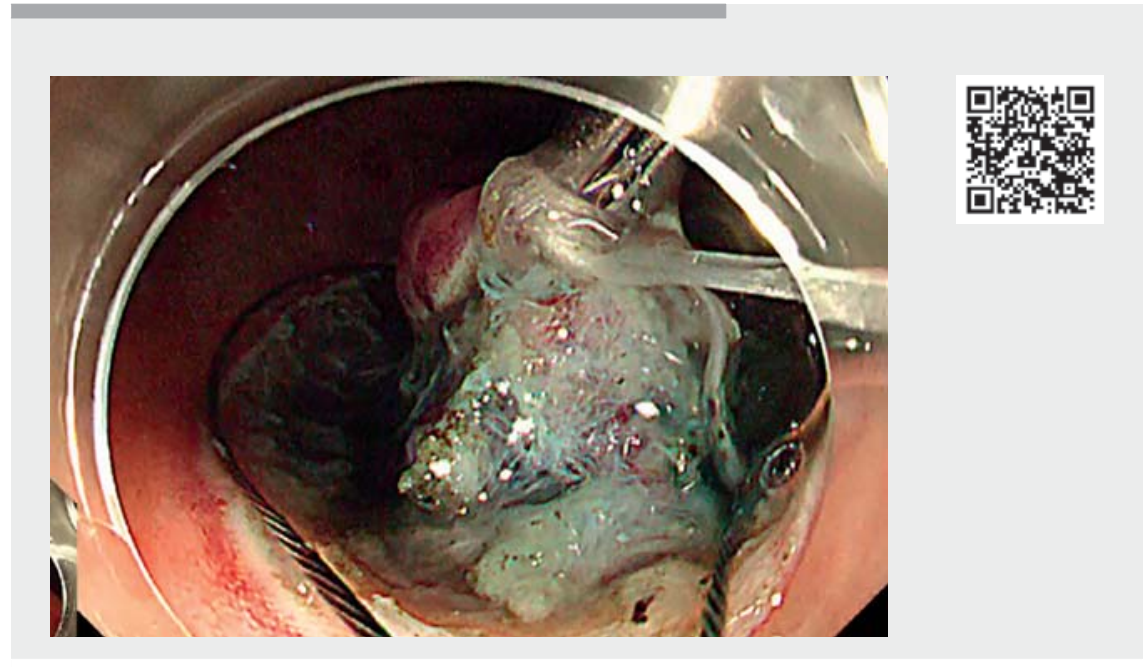

Video 1 Traction-assisted hybrid endoscopic submucosal dissection for small rectal neuroendocrine tumors. Source for the snare: Kaneka Medix. Source for graphical illustrations: Hiroko Fujisawa.

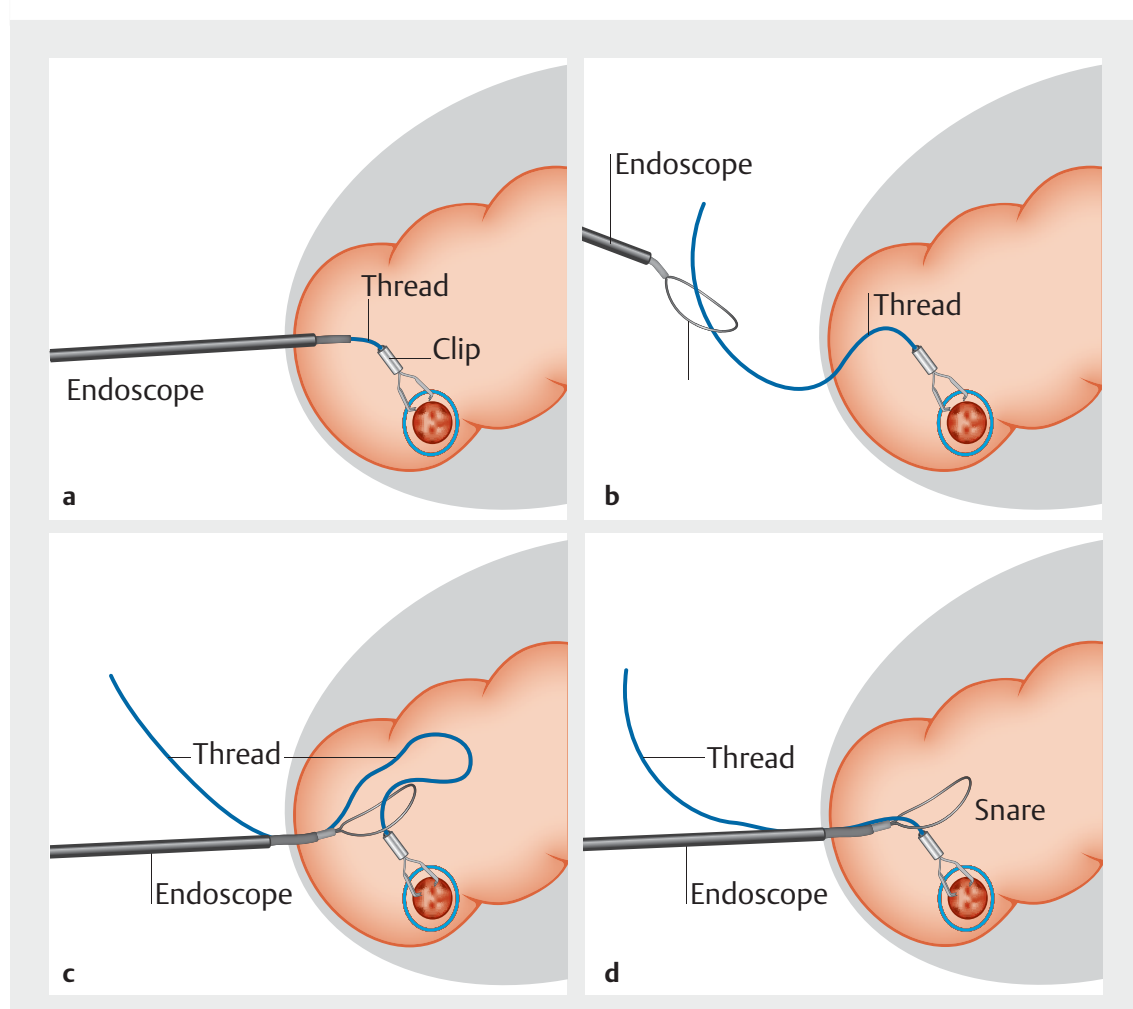

- Fig. 1 Schemata showing the step-by-step procedure for traction-assisted hybrid endoscopic submucosal dissection. a A clip-with-thread was placed at the anal part of the lesion. $\mathbf{b} \mathrm{A}$ thread was passed through a ring of the snare being inserted through an endoscopic channel. c The endoscope was inserted into the rectum. $\mathbf{d}$ The lesion was elevated by pulling the thread. 


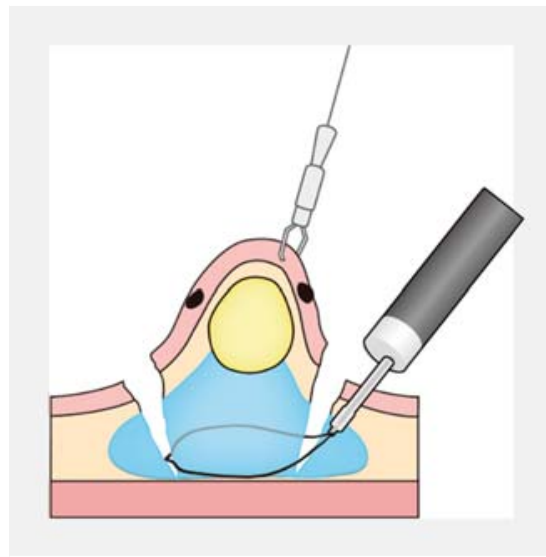

- Fig. 2 Schemata of traction-assisted hybrid endoscopic submucosal dissection for a small rectal neuroendocrine tumor. Source: Hiroko Fujisawa.

Traction-assisted hybrid endoscopic submucosal dissection enables deeper dissection of the submucosa by vertical traction of the lesion, which is effective for rectal NETs involving the submucosal layer.

Endoscopy_UCTN_Code_TTT_1AQ_2AD

Acknowledgments

The authors thank Shinya Umekita for histological assessment. The authors thank Hiroko Fujisawa for creating illustrations.

\section{Competing interests}

Eikichi Ihara participated in a funded study of Takeda Pharmaceutical Co., Ltd. and belongs to the endowed course supported by the companies mentioned, including Ono Pharmaceutical Co., Ltd., Miyarisan Pharmaceutical Co. Ltd., Sanwa Kagaku Kenkyusho Co., Ltd., Otsuka Pharmaceutical Factory, Inc., Fujifilm Medical Co., Ltd., Termo Corporation, Fancl Corporation, and Ohga Pharmacy.
Eikichi Ihara received a lecture fee from Takeda Pharmaceutical Co. The other co-authors have no conflicts of interest or financial ties to disclose.

The authors

Takayuki Nasu', Mitsuru Esaki ${ }^{1,2}$, Yoshihisa Shoguchi ${ }^{1}$, Xiaopeng Bai ${ }^{1}$, Yosuke Minoda ${ }^{1}$, Haruei Ogino ${ }^{1}$, Eikichi Ihara ${ }^{1,3}$

1 Department of Medicine and Bioregulatory Science, Graduate School of Medical Sciences, Kyushu University, Fukuoka, Japan

2 Division of Gastroenterology and Hepatology, Department of Medicine, Nihon University School of Medicine, Tokyo, Japan

3 Department of Gastroenterology and Metabolism, Graduate School of Medical Sciences, Kyushu University, Fukuoka, Japan

\section{Corresponding author}

\section{Mitsuru Esaki, MD}

Department of Medicine and Bioregulatory Science, Graduate School of Medical

Sciences, Kyushu University, 3-1-1, Maidashi, Higashi-ku, 812-8582, Fukuoka, Japan Fax: +81-92-642-5286

esaki.mitsuru.832@m.kyushu-u.ac.jp

\section{References}

[1] Nakamura K, Osada M, Goto A et al. Shortand long-term outcomes of endoscopic resection of rectal neuroendocrine tumours: analyses according to the WHO 2010 classification. Scand J Gastroenterol 2016; 51: 448-455. doi:10.3109/ 00365521.2015 .1107752

[2] Sekiguchi M, Sekine S, Sakamoto T et al. Excellent prognosis following endoscopic resection of patients with rectal neuroendocrine tumors despite the frequent presence of lymphovascular invasion. J Gastroenterol 2015; 50: 1184-1189. doi:10.1007| s00535-015-1079-7
[3] Yamashina T, Tumura T, Maruo T et al. Underwater endoscopic mucosal resection: a new endoscopic method for resection of rectal neuroendocrine tumor grade 1 (carcinoid) $<=10 \mathrm{~mm}$ in diameter. Endosc Int Open 2018; 6: E111-E114. doi:10.1055/s0043-123467

[4] Esaki M, Maehara R, Nagatomo S et al. Application of traction-method to hybrid endoscopic submucosal dissection for gastrointestinal tumors. Endoscopy 2021. doi:10.1055/a-1422-2902

[5] Ohata K, Muramoto T, Minato Y et al. Usefulness of a multifunctional snare designed for colorectal hybrid endoscopic submucosal dissection (with video). Endosc Int Open 2018; 6: E249-E253. doi:10.1055/s-0043124364

Bibliography

Endoscopy 2022; 54: E550-E551

DOI 10.1055/a-1662-4965

ISSN 0013-726X

published online 19.11.2021

(c) 2021. Thieme. All rights reserved. Georg Thieme Verlag KG, Rüdigerstraße 14, 70469 Stuttgart, Germany

\section{ENDOSCOPY E-VIDEOS}

https://eref.thieme.de/e-videos

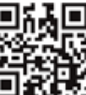

Endoscopy E-Videos is an open access online section, reporting on interesting cases and new techniques in gastroenterological endoscopy. All papers include a high quality video and all contributions are freely accessible online. Processing charges apply (currently EUR 375), discounts and wavers acc. to HINARI are available.

This section has its own submission website at https://mc.manuscriptcentral.com/e-videos 